\title{
cone sul em transe
}

\section{de Vinícius Bandera ${ }^{1}$}

Não completara três semanas que Reyes fora elogiado em Boletim Interno pelo próprio comandante da unidade, por ter sido o primeiro a chegar ao local do incêndio provocado pelos "subversivos inimigos da pátria", à frente dos quais um ex-capitão daquele mesmo Exército. "Não fosse o seu heroísmo o nosso paiol de munição teria ido pelo ares, parabéns cadete", asseverou o general-comandante enquanto colocava, muito sem jeito, a medalha na túnica de Reyes, do lado esquerdo do peito, no centro do coração, chegando mesmo a espetá-lo por duas vezes. Reyes riu por dentro, mas passou ao general uma expressão correspondente a que normalmente seria condizente com o momento. Atrás de Reyes a tropa estava perfilada em sua homenagem e, em um dado momento, todos apresentaram armas à bandeira, em obediência ao toque do cabo corneteiro. Nesse momento, dois olhares inamistosos se encontraram: um era de Reyes, outro era do comandante da $3^{\text {a }}$ Companhia, o capitão Durando. Ambos, firmemente, apresentavam armas; o primeiro com espadim, o segundo com a espada. Durando estava no segundo degrau da escada, a dois passos atrás do general-comandante. Por dentro o ódio o corroía; tanto que a espada tantas vezes erguida, naquele instante pesava mais do que cruz de Jesus. Reyes, vitorioso, por dentro sorria satisfeito e mudo, encarando o capitão de soslaio. Ao toque de descansar seguiu-se o discurso do general, cujo tema indefectivelmente abordava o incitamento ao cuidado ao perigo subversivo. Nesse momento, o olhar de Reyes descreveu uma panorâmica pelo pátio

1 Pós-doutorado História (USP). Doutorado Sociologia (UFRJ). Mestrado Ciência Política (UNICAMP). Autor dos livros Ordenação social no Brasil (Editora UFRJ); Náufragos da fé (Laço Editorial); Mulheres da vida (Multifoco) e A genealogia em Foucault: do poder soberano ao poder panóptico (NEA Edições) 
interno do quartel procurando os olhos esverdeados do sargento Lorenzo. Não foi difícil encontrá-los, porque Lorenzo, do alto de seus 1,90m, estava sempre à testa da Companhia de Comando e Serviços, metralhadora em posição de descansar e pronta para qualquer tipo de ação. Lorenzo tinha os seus olhos pregados no general-comandante, que continuava o seu discurso. Mas, como que atraído pelo olhar de Reyes, o sargento meneou a cabeça para o lado esquerdo e deu com os olhos nos que aos seus buscavam. Os dois se comunicavam à sua maneira. Logo depois, ouviram-se gritos de "fora de forma", emanados pelas gargantas dos comandantes de companhias. Reyes havia comunicado a Lorenzo que precisava falar-lhe àquela noite sem falta, no lugar de sempre. Alguma coisa estava por acontecer e os dois precisavam tomar as devidas precauções.

No dia da descoberta, Reyes fora acordado em seu alojamento com um tapa em pleno rosto dado pelo seu arqui-inimigo, o capitão Durando: "Traidor filho da puta, a mim você nunca enganou!". A isto, seguiu-se uma sessão de pancadaria que veio a confirmar as suspeitas de Reyes. Lorenzo, que também o torturava, vivia dizendo-lhe que tais suspeitas não passavam de paranoia devido a sua inexperiência na luta, e o aconselhava a que mantivesse a sua vida normalmente, porque não havia o que temer. Lorenzo cometera um erro de avaliação, pensava Reyes enquanto levava uma surra em que se destacavam os golpes do sargento grandalhão. Reyes jamais imaginou que um dia viria a sentir o peso daquela canhota, famosa em todo o quartel nas lutas de boxe, que às vezes chegava a enfrentar três, cinco, homens de uma só vez. Porém, os golpes que mais doíam vinham de Durando. Até que, não mais aguentando, perdeu os sentidos, parecia-lhe que era a morte.

Reyes despertou com os raios solares a penetrarem por entre o orifício quadrado da cela, batendo em seu rosto. A princípio, não entendera bem de que se tratava, depois foi que compreendeu que estava vivo, e pela primeira vez em sua vida lamentou essa tragédia. Não demorou muito para que a portinhola se abrisse e ele divisasse, por entre a vista amassada, as figuras de Durando, Lorenzo e um paisano, o qual ele jamais vira.

Lorenzo não conseguia fitar-lhe. Isso fez com que com um medo maior se assomasse ao que Reyes já sentia. "E se Lorenzo não fosse capaz de aguentar a situação?", questionou-se Reyes, que já estava resolvido a morrer calado, já se havia condenado, e poderia ser naquela sessão. Fazia um esforço quase sobre-humano para abrir os olhos o mais que pudesse, suportando a dor 
insuportável, para dizer a Lorenzo que não se deixasse trair pelo coração, que continuasse o seu papel. Lorenzo sabia que o olhar de Reyes estava sobre si, mas não tinha coragem de encará-lo. Os dois já estavam preparados para o grande golpe do dia 26, a queda de Reyes poderia pôr tudo a perder, porque de posse deste estava o comando da maior parte da ação. A não ser que Lorenzo assumisse o comando-geral. Era isso que Reyes tentava expressarIhe quando ouviu a voz de Durando:

- Vamos fazer-Ihe mais uns carinhos, eu sei que você gosta!

Mais uma vez, Lorenzo fora incumbido de fazer os "carinhos". Quem mandara ele ser tão forte? Nesse momento, os dois olhares se encontraram: o de Reyes exigia maior determinação nos golpes, o de Lorenzo revelou uma dor maior do que a que o torturado sentia. Ao escutar o berro do capitão, Reyes, por um instante, pensou ter o carrasco descoberto a farsa.

- Vamos com isso seu imbecil, eu falei carinho por ironia, sargento burro!

Reyes chegara ao limite de suas forças, mais uma vez o desmaio funcionou como o gongo em luta de boxe.

As imagens foram-se esmaecendo, os golpes se tornaram anestesiados, a cabeça não pensava, ele sentia a morte, e se sentia feliz por ter-se portado como sempre esperara de si. Sabia que Lorenzo iria multiplicar tantas vezes quanto possível o seu comportamento quando levasse a notícia aos companheiros, naturalmente iria omitir a sua participação no caso. Lorenzo perpetuaria a sua memória, e o que mais importava a Reyes é que de sua boca seus inimigos não saberiam de nada, ele iria morrer pagão, sem confessar a seus inquisidores.

O dia seguinte era véspera de Natal e isso propiciou uma trégua a Reyes, por que o capitão Durando, como bom cristão que era, resolvera não lhe torturar até que passasse o efeito do nascimento do Redentor. Reyes, apesar de seu agnosticismo, agradeceu ao Messias por ter nascido em data tão favorável a ele. Seriam uns três dias sem tortura. Uns três dias para Reyes recuperar-se do que resultaria em sua morte certa, pois lhe parecia que Lorenzo não tinha esperanças de que ele confessasse qualquer coisa. $\mathrm{E}$ a ordem naqueles tempos era matar. Matar a quem confessasse e matar a quem não confessasse. Era assim a maneira mais rápida e prática de se acabar com a espécie daqueles subversivos. Reyes ainda não podia sentar-se, 
muito menos deitar de bruços. Tinha a impressão de ter qualquer ruptura interna, além de algumas costelas partidas. Dos olhos, só o esquerdo era possível abrir, o suficiente para enxergar as paredes embaçadas da solitária. O olho direito, ele acreditava estar cego. Ficou deitado de lado, encolhido como se estivesse com muito mais frio do que sentia, sem poder mover-se porquanto a dor aumentava insuportavelmente a qualquer movimento por mais imperceptível que fosse. Reyes esperava e se surpreendia com a sua ausência de desespero. Pensou no ditado que diz que a esperança é a última que morre. E se surpreendeu mais ainda por que no fundo, contrariando o seu realismo, ele tinha esperança de que tudo acabasse bem para si. Só que ele não sabia como isso se daria. Pensou em Serena que àquela hora já devia estar cansada de esperá-lo na rodoviária.

Imaginou-a fumando um cigarro atrás do outro, andando de um lado para outro, sem saber o que fazer. Combinaram aproveitar o Natal para se refugiar no sítio de um tio dela, lá estudariam a ação do dia 26 e continuariam a lua de mel tantas vezes interrompida. Na certa, Serena tentaria entrar em contato com ele, via quartel, e não teria qualquer informação concreta a respeito de seu paradeiro. Isso significaria, para ela, que ele caíra e deveria estar sendo torturado, provavelmente ali mesmo no quartel. Serena procuraria entrar em contato com Lorenzo (se este não a procurasse antes) e este lhe confirmaria as suas suspeitas. Ela, impetuosa e apaixonada, proporia na reunião com o grupo (convocado às pressas) uma operação de salvamento, antes que fosse tarde. Possivelmente haveria um consenso em torno dessa proposta, a não ser que Ramon e Luna se posicionassem contra, querendo salvaguardar a operação do próximo dia 26 e também por não acreditarem no êxito da missão. Reyes imaginava que àquela hora o grupo, ou estaria reunido, ou já se reunira, ou estaria por fazê-lo. Temia que seus companheiros apelassem para uma operação-resgate, que, a seu ver, seria totalmente inexequível, pois o quartel estava suficientemente defendido para repelir qualquer tentativa dessa espécie. Reyes esperava que seus companheiros fossem sensatos e deixassem de lado a hipótese de querer salvá-lo e se concentrassem na ação do dia 26; esta sim, de vital importância para o futuro da luta. Reyes esperava que Ramon e Luna, os mais sensatos e frios, convencessem os outros companheiros, principalmente Serena e Lorenzo, da impossibilidade de qualquer gesto de resgate. E esperava mais ainda, que seus companheiros não deixassem de cumprir o programado para o dia 26, que confiassem que 
de sua boca não sairia qualquer palavra que viesse a comprometer a ação, que acreditassem que ele iria morrer de boca fechada.

A portinhola da solitária abriu-se e Lorenzo teve que se abaixar para penetrar no interior da mesma. O olho esquerdo de Reyes, apesar de reproduzir uma visão desfocada, conseguiu divisar aquele corpanzil. O sargento, com o coração partido diante do que via, ficou por um momento sem saber o que fazer ou mesmo o que dizer. Reyes nada falou porque não podia. Naquele momento, ele percebeu que não podia abrir a boca. Mesmo assim, forçou o olhar, proveniente do olho esquerdo, de encontro ao olhar de Lorenzo.

- Nós iremos tirá-lo daqui esta noite! - disse o sargento, com a fala embargada pela emoção.

Lorenzo não entendia a reação de Reyes, que tentava dizer-lhe para desistirem dessa ideia absurda, por ser impossível de ser levada a efeito e por deitar por terra a ação do dia 26 . O sargento abaixou-se aproximando-se dele, apalpando-o como para sentir a gravidade de seu estado. Reyes fitou o companheiro com firmeza, querendo dizer-lhe para não tentarem tirá-lo dali. Lorenzo nada entendia do que ele dizia, nem com isso estava preocupado. A sua intenção era amenizar as dores do companheiro e trazer-lhe alimentação, além de dar-lhe a notícia que dera. Reyes bebeu com sofrimento uma vitamina de frutas que Lorenzo deu-lhe através de colheradas. Depois sentiu a picada de uma agulha em sua veia, que fez com que, em segundos, o seu corpo se tomasse vítima de uma dormência geral que o impediu de sentir qualquer tipo de dor. Daí a pouco, um sono profundo tomou conta do torturado. Lorenzo cumprira a sua primeira parte na missão. O companheiro não sofria mais, dormiria até que viesse a noite, quando, então, o grupo dividido em vanguardas, iria resgatá-lo para a liberdade. Caberia a Lorenzo provocar a explosão do paiol de munições, o que deslocaria o grosso da segurança do quartel para o local do sinistro, quando os demais companheiros de Reyes entrariam em ação para libertá-lo.

Pelos papéis encontrados no escaninho de Reyes, a repressão pôde deduzir que uma grande ação estava para ser efetuada nos próximos dias, e era isso que Durando e outros queriam arrancar de Reyes antes de matá-lo. Nas sessões de tortura o que doía mais em Reyes era a sua imprevidência, fato que poderia comprometer toda a organização. Na verdade, aqueles papéis eram para ter sido queimados na noite anterior ao dia que Durando os encontrou. 
Ele se julgou totalmente culpado e irresponsável, foi o que concluiu após recuperar-se da primeira sessão de tortura. Não queria que Serena soubesse dessa sua falta, sabia que por intermédio de Lorenzo (o único do grupo que sabia) ela jamais iria saber de nada.

A injeção aplicada por Lorenzo fora suficiente para fazer Reyes dormir não mais que duas horas, as dores por todo o corpo eram mais fortes do que qualquer analgésico. Mas, mesmo assim, ele achou bom ter tido umas duas horas de alívio. Acordou com a cabeça mais refrescada, apesar das dores embaçarem o seu raciocínio. O que lhe veio à mente, de imediato, logo após despertar e soltar um longo gemido por ter se movido ao esquecer-se de sua situação, foi a operação que seus companheiros tramavam para resgatá-lo. Ele ainda não podia imaginar como um grupo de no máximo quinze pessoas, entre homens e mulheres, com armamentos rudimentares, poderia invadir um quartel que contava com um efetivo de quase duzentos homens, tendo à sua disposição o que de mais moderno havia em armamentos. Em sua cabeça, ele tentava imaginar as várias fórmulas para um resgate desse tipo. Ele, que conhecia tão bem a cabeça dos companheiros, chegou à conclusão de que, ou eles desistiriam do resgate, ao constatarem a sua impraticabilidade, ou cometeriam um suicídio coletivo. É claro que, véspera de Natal, os quase duzentos homens não estariam no quartel, mas, como todos os quartéis do país viviam em estado de prontidão, justamente para evitar surpresas daquele tipo, era certo que pelo menos cinquenta homens bem alertas e bem armados, além de bem treinados, estariam naquele momento guardando aquele batalhão de infantaria. O sentimento de companheirismo o comoveu, ele faria o mesmo por qualquer companheiro, mesmo, é lógico, que fosse pelo Ramon, com o qual estava brigado, por este o ter acusado de desvio ideológico, pelo simples fato de Reyes ter passado uma semana com Serena no sítio. Na volta, provocado por Ramon, os dois discutiram e chegaram às vias de fato. Ninguém se meteu na briga, que demonstrou uma leve superioridade de Reyes. A partir daí, a grupo se dividiu em duas facções, os favoráveis a Ramon e os favoráveis a Reyes. Os dois passaram a se estranhar a tal ponto, que todos sabiam que em caso de nova briga as automáticas iriam falar ao invés dos punhos. Sabedores disso, os dois procuravam evitar o confronto para não haver derramamento de sangue dentro do coletivo. Reyes lamentou a briga com o companheiro, mas sabia que mais dia, menos dia, isso iria acontecer de novo, dado o sectarismo ideológico de Ramon; o que levou Reyes a chamá-lo, no momento mais áspero da discussão, de reacionário 
de esquerda e conservador proletário, obreirista demagogo e outras coisas desse nível. Não mais continuou a enumerar as inúmeras "qualidades" do companheiro por que este o calou com um soco em plena boca. A partir daí, não mais se xingavam, mas se golpeavam. Serena pediu que os dois parassem com aquela estupidez que só servia para dividir o grupo. Chegou mesmo a meter-se na briga, a favor de Reyes, é claro, mas logo foi contida pelos outros companheiros, que achavam que os dois tinham o direito de resolver as divergências segundo as suas vontades. Então, foram satisfeitas as vontades dos dois contendores, que brigaram até que caíram lado a lado. Se houvesse um julgamento honesto para a luta, Reyes teria sido declarado vencedor, por que só desmaiou alguns minutos depois de Ramon. Aliás, Reyes não desmaiou, fora vencido pelo cansaço, ao contrário de Ramon que perdera os sentidos após o último soco do companheiro, que lhe atingira a boca do estômago, fazendo-o emitir um som gutural à semelhança dos que os animais emitem quando atingidos por um golpe contundente.

Na verdade, fora imerecido o elogio que Reyes recebera através do Boletim Interno por ter salvo o paiol de munições, pois fora ele próprio quem ateara fogo no paiol. Quando percebeu que poderia ser incriminado pelo ato, pois várias pessoas, entre as quais Durando, já se dirigiam ao local atraídas pela fumaça, então começou a gritar por socorro, como se estivesse chegando naquele momento, e a tentar apagar o fogo como podia. Logo, todos estavam no local do crime. Como o fogo estava em seu princípio, não foram precisos mais do que alguns extintores de incêndio para debelar as chamas que iriam pôr tudo pelos ares. Reyes tornou-se o herói do dia. Seus colegas o carregaram nos ombros e deram vários hurras em sua homenagem. 0 general-comandante o abraçou demoradamente, depois o convidou para almoçar em sua mesa no refeitório dos oficiais. De longe, Durando morria de ciúmes. Na hora do fogo, ele ficou desesperado sem saber o que fazer, ainda mais que a guarda do paiol cabia à sua responsabilidade. Fora Reyes que coordenara toda a operação-salvamento. Reyes estava acostumado a ações desse tipo, em que era necessário coragem e sangue-frio, se bem que as suas ações voltavam-se contra o governo defendido pelo general-comandante e pelo capitão Durando. Enquanto comia, frente a frente com o comandante, tendo por demais companhias à mesa, os coronéis Javier e Lajedo, Reyes imaginava o estrago que faria uma bomba naquele ambiente. "Seriam cacos de galões pra tudo que é lado", pensou, rindo entre os dentes, no momento exato em que o coronel Lajedo, na tentativa de bajular o general, 
contou-lhe uma piada que generalizou o riso à mesa. Reyes nunca imaginara que um dia viria a sentar-se à mesma mesa com o general Diaz, ainda mais como convidado de honra. O fato provocou brincadeiras diversas por parte de seus colegas cadetes, até nas privadas tinham rabiscado chistes sobre o almoço. Por imposição do general, Reyes passou a ser o chefe de sua turma, função a que ele nunca almejara.

A primeira rajada de metralhadora seguida de intenso tiroteio, fez com que Reyes saísse de suas lembranças e tentasse, à custa de um desesperado esforço, erguer-se em direção ao orifício quadrado da cela, que servia de janela, por onde passava malmente o ar. Seu esforço não logrou êxito. Mas não foi necessário ele ver para compreender o que se passava lá fora, em noite alta. Os tiros de armas pesadas sobressaiam-se aos tiros de revólveres. Aliado a isso, ele pôde escutar gritos de dor vindo de vozes conhecidas, dentre as quais ouviu um grito nítido de mulher que poderia ou não ser de Serena. Isso doeu mais do que a dor que sentia, que o fez esforçar-se ainda mais em uma nova investida de colocar os olhos no quadrado, para ver a carnificina que ele imaginava estar havendo lá fora. Novamente não conseguiu erguerse. Juntamente com gritos de dor vindo dos seus companheiros, escutava gritos dos defensores do quartel. Eram gritos de comando, de ira. Pouco depois, escutou explosões de granada que sabia não serem lançadas por seus companheiros, pois eles não as possuíam. O tiroteio continuou por algum tempo mais. Reyes desistiu definitivamente de tentar mover-se. Sabia que a sorte estava lançada para si e seus companheiros. O que mais lamentava era não estar também lá fora lutando junto com os seus, pelo menos morreria em combate ao invés de morrer na tortura.

O tiroteio, devido à desigualdade de forças, não durou mais do que duas horas. Depois o barulho dos tiros foi substituído por uma euforia traduzida pelo burburinho de vozes dos defensores do quartel. Reyes, deitado no chão, encolheu-se ainda mais, devido ao frio, à sua dor e a dor provocada pelo que seus ouvidos testemunhavam.

Num dado momento, a porta da cela se abriu e seus olhos, ao se voltarem, depararam-se com os de Durando. O sorriso do capitão confirmou a sua impressão sobre qual lado houvera sido o vencedor. 